\title{
СОВРЕМЕННЫЕ ПРОБЛЕМЫ ОЦЕНКИ ЭФФЕКТИВНОСТИ МЕХАНИЗМОВ СТРАТЕГИЧЕСКОГО УПРАВЛЕНИЯ
}

\section{Ларионова М.А.} К.ю.н., доцент кафедры правовых дисциплин и методики преподавания права ФГБОУ ВО «Пермский государственный гуманитарно-педагогический университет» аспирант кафедры менеджмента ФГАОУ ВО «Пермский государственный национальный исследовательский университет»

Аннотация: настоящая статья посвящена вопросу проблемы определения критериев оценки эффективности стратегического управления. В ходе статьи автором анализируется порядок определения как подбора соответствующих критериев, целей оценки, так и определения методики, по которой предполагается возможность выбора такой оценки. В заключении статьи, автор приходит к выводу, что определение критериев оценки эффективности стратегического управления, обусловлено не только объективными, внешними факторами, такими как воздействующее влияние субъекта управления на объект управления, но и внутренними качественными показателями самого стратегического управления.

Ключевые слова: стратегическое управление, оценка, объект управления, эффективность, показатели.

\section{MODERN PROBLEMS OF ASSESSING THE EFFICIENCY OF STRATEGIC MANAGEMENT MECHANISMS}

Larionova M.A.

\begin{abstract}
This article is devoted to the problem of determining the criteria for assessing the effectiveness of strategic management. In the course of the article, the author analyzes the procedure for determining both the selection of appropriate criteria, the objectives of the assessment, and the determination of the methodology by which the possibility of choosing such an assessment is assumed. At the end of the article, the author comes to the conclusion that the definition of criteria for assessing
\end{abstract}


the effectiveness of strategic management is determined not only by objective, external factors, such as the influence of the subject of management on the object of management, but also by the internal quality indicators of the strategic management itself.

Key words: strategic management, evaluation, management object, efficiency, indicators.

Эффективность оценки может трактоваться в различных аспектах, так, например, Новиков Д.А. характеризует его в двух аспектах: как процесс и как результат «измерения». «Состояние системы описывается некоторыми

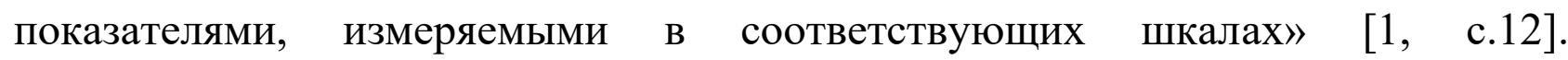
В отношении процесса представляет собой процесс описания системы в определенных шкалах. Эффективность системы может определяться ее результатом, т.е. зависимость состояние системы критериям оценки. Выбор критериев может зависеть от целей оценки.

Проблема оценки эффективности механизмов стратегического управления неразрывна связана с объектом управления. Так, С. В. Комаров, С. И. Кордон, в своей книге «Основы методологии: системодеятельностный подход. Категории», сравнивают объект управления с кентавр-объектом, указывая на дуальность этого понятия, вбирающее в себя две особенности: с одной стороны, объект управления подчиняется своим, внутренним законам, с другой законам той деятельности, в которую он вовлечен [2, с. 73].Объект управления в современных экономических условиях имеет возможность изменяться и развиваться, как под воздействием внутренних факторов, так и внешних условий, что характеризует его как динамическое явление, нуждающееся в гибких инструментах управления, с целью выхода за пределы ранее известной системы, при которой компания способна к функционированию. В данном контексте уместно указать, что для стратегического управления характерен перспективный, а не ретроспективный выбор инструмента воздействия на объект управления, т.е. механизм управления, в момент подготовки стратегического планирования отсутствует или еще не адаптирован к конкретной ситуации, следовательно, его необходимо создать или сконструировать. В связи с чем, мы можем констатировать проблему определения оценки эффективности механизмов стратегического управления, а именно, отсутствие апробации механизма стратегического управления. Это вытекает из того, что отсутствует универсальный механизм 
стратегического управления. Стратегия предполагает адаптацию универсального к индивидуальному.

Таким образом, определяя критерии оценивания результата стратегического управления, необходимо учитывать не только условия внешнего воздействия на объект, при применении инструментов управления, но и особенности самого объекта, который может развиваться по иной, отличной от предполагаемого процесса управления, траектории, не подчиняясь внешнему воздействию, а исходя сугубо из внутренних особенностей. При этом объект так или иначе подчиняется внешнему управленческому воздействию, тем самым «тормозя» проявление индивидуальных свойств, подчиняясь общей поставленной цели. Предполагается, что оценка эффективности выбранных механизмов стратегического управления, будет зависеть, насколько такое «торможение» или изменение траектории развития объекта воздействия подстраивается под сконструированный план стратегического управления.

Для стратегического управления характерно наличие нескольких сценариев развития деятельности и реагировании компании на внешние условия, выбор миссии компании и ее реализации. И если для обычного управления характерна бинарная система оценки: выполнено / не выполнено, то для стратегического управления необходимы иные подходы к оценке его результатов.

Методика выбора оценки эффективности стратегического планирования, может быть избрано два измерения - экономическое и результативное. Результативное может быть представлено с точки зрения, оценивания получение запланированных результатов с состоянием системы (предприятия). Экономическое, является переменным показателем, поскольку соизмеряется совокупностью затрат и результатом [3].

Оценка результатов, как один из механизмов определения эффективности стратегического планирования, также имеет ряд проблем, а именно, как правило оценке подвергаются результаты, достигнутые не в ходе стратегического, а оперативного управления, которое как правило имеет количественные показатели, например, увеличение прибыли.

«Наличие измеримого результата (без которого управление невозможно), позволяет оценивать степень достижения цели как предвосхищаемого, ожидаемого результата деятельности. Эффективность деятельности - степень соответствия ее результата целям субъекта, осуществляющего деятельность. Осуществляя воздействия на компоненты деятельности - управляя ими, - 
можно влиять и на результат деятельности и, следовательно, на эффективность деятельности в целом» [1].

Кроме этого, для стратегического планирования, характерно, что он не может определить конечный результат в количественных показателях. Стратегическое управление нацелено на формирование качественного состояния компании в будущем, сможет ли продолжить свое функционирование, какое место на рынке может занять. Следовательно, подобрать универсальную методику оценки эффективности стратегического управления, также представляется затруднительным.

Таким образом, мы можем заключить, что современные проблемы оценки эффективности стратегического управления, обусловлены не только внешними условиями, такими как управленческое воздействие на объект управления, но и внутренними факторами, связанными с особенности стратегического управления, которое само по себе не имеет цели достигнуть количественных показателей, а направлено на достижение качественного результата.

\section{Список литературы}

1. Новиков Д. А. Методология управления. - М.: Либроком, 2011. $128 \mathrm{c}$.

2. Основы методологии: системодеятельностный подход. Категории. / С.В. Комаров, С.И. Кордон. - Пермь: Изд-во Перм.гос.ун-та, 2005. 384 с.

3. Трунова С. Н. Комплексная методика оценки эффективности стратегического управления развитием сельскохозяйственной организации // ТППП АПК. 2015. №2 (6). С. 89-96.

(C) М.А. Ларионова, 2022 